\title{
RELIEVE DEL TEMPLO MAYOR CON TLÁLOC TLALTECUHTLI Y TLÁLOC
}

NELLY GUTIÉRREZ SOLANA A Gracy Solana de Arizpe

La pieza que aquí estudio ha llamado la atención desde que fue desenterrada por el hecho de que, a primera vista, la figura representada parece tener dos caras y un solo cuerpo. Se trata de un monolito trabajado en relieve que fue hallado, durante las excavaciones de marzo a mayo de 1978, en la fachada posterior del basamento piramidal del Templo Mayor, fachada que da al este. Esta pieza fue descrita brevemente por Cecilia Klein en su artículo Who was Tláloc? publicado en 1980 pero considero que es de interés realizar un estudio interpretativo más amplio y más profundo que incluya además el fragmento menor de la obra que anteriormente no estaba exhibido.

Según nos dice su descubridor, el arqueólogo Eduardo Matos, el monolito se encontró debajo de la capa de relleno moderno y conservaba restos de pigmento rojo y negro ${ }^{1}$ además pueden apreciarse restos de estuco en uno de los adornos cercanos a la falda. La pieza está incompleta y fracturada pero los relieves se conservan en buenas condiciones lo que permite la identificación de la mayoría de los elementos tallados. Las medidas actuales del monolito son $131 \mathrm{~cm}$ de largo, $88 \mathrm{~cm}$ de ancho y el espesor es de aproximadamente $32 \mathrm{~cm}$ aunque es bastante irregular. La forma general de la pieza era probablemente parecida a la del relieve casi circular de la Coyolxauhqui. El labrado de la pieza es de buena calidad y los detalles se representaron con todo cuidado. El relieve presenta diferentes grados de proyección como puede verse particularmente en las calaveras de la falda que sobresalen de manera notoria.

En el monolito hay una figura con rostro y cuerpo y de su boca parece emerger otra cara. No se trata de un rostro con tocado, como se le ha descrito, puesto que los miembros superiores salen a los lados de la cara

${ }^{1}$ Matos, 1982, p 19 
unida al cuerpo y, por lo tanto, este no podría ser el tocado. La figura muestra los cuatro miembros flexionados a los lados del cuerpo (tres de ellos incompletos), los senos al descubierto y la cabeza está echada hacia atrás (figura 1 y 2 ).

El rostro de la figura tiene aros alrededor de los ojos y las cejas se enrollan formando volutas a los lados de los mismos (figura 2). La nariz es del tipo humano, en cambio la boca se compone de cuatro grandes colmillos debajo del labio superior el cual se continúa a los lados de ellos. El tocado consiste en una franja con tres discos en su interior y de cintas colgantes de bordes aserrados. Otros rasgos de interés son: el símbolo ollin que lleva en el centro del cuerpo, como pectoral, la falda con calaveras y huesos cruzados y las tiras con cráneos colgantes en los brazos y piernas (sólo quedan restos de dos de ellos) (figura 3). A los lados de la falda se labraron lo que parecen ser adornos con chalchihuites los cuales presentan, en un lado, bordes con recuadros decorativos y, en el otro, caracoles y chalchihuites. Como dije anteriormente los miembros están incompletos pero gracias al fragmento menor podemos ver uno de los miembros inferiores que parece conservar restos de una sandalia que se amarraba sobre el empeine. Contiguo a la parte central de la falda hay un diseño que probablemente sea un glifo y al cual me referiré posteriormente.

El otro rostro; que es el emergente, se puede identificar como el de Tláloc, el Dios de la Lluvia, por los círculos alrededor de los ojos redondos, la nariz con ranuras en diagonal y la boca con colmillos alargados y curvos que emergen del labio superior y el tocado de papel plegado que flanquea a la cara. ${ }^{2} \mathrm{~A}$ los lados de dicho tocado emergen chorros de agua con espirales, chalchihuites y caracoles en un diseño que recuerda al de las corrientes acuáticas que salen de la diosa labrada en relieve en el Cerro de la Malinche cercano a Tula, en el estado de Hidalgo (figura 4). Este relieve rupestre pertenece también a la cultura mexica. En ambos extremos del monolito, en lo que son sus bordes que no están destruidos, hay tallas relacionadas asimismo con el agua. En el borde cercano al rostro de Tláloc aparece una serpiente de cuerpo ondulante con la cabeza de perfil y la lengua bífida representada de frente, además de símbolos acuáticos como corrientes de agua, chalchihuites, espirales y caracoles. En la orilla cercana a la falda con calaveras, ya mencionada, hay los mismos signos acuáticos y lo que parece ser un animal cuadrúpedo.

\footnotetext{
${ }^{2}$ Este es el Tláloc que Pastory, 1974, identifica como el Tláloc A de Teotihuacan asociado principalmente a la lluvia.
} 
La figura con cara y cuerpo, a la cual me referí anteriormente, ha sido identificada como un monstruo terrestre con rostro de Tláloc por Cecilia Klein en el artículo ya mencionado al cual acompaña un dibujo que no incluye al fragmento menor. ${ }^{3}$ Tláloc no era únicamente la deidad de la lluvia sino además de la tierra y del inframundo. En la Historia de los Mexicanos por sus pinturas se le llama Dios del Infierno ${ }^{4}$ o sea del inframundo y en la Histoire du Mexique se habla de Tlalocateutli, como Dios de la Tierra. ${ }^{5}$ Thelma Sullivan considera que la palabra Tláloc originalmente se escribía con doble 1 y significaba el que tiene la cualidad de la tierra ${ }^{6}{ }^{6}$ Por lo tanto se puede identificar a la figura como Tláloc Tlaltecuhtli el cual corresponde al Tláloc B de Teotihuacan aunque con modificaciones tanto en sus rasgos característicos como en sus significados. Ya hablamos anteriormente de que la figura del monolito tiene la cabeza echada hacia atrás en una posición anatómicamente imposible porque estamos viendo el frente del cuerpo, como lo indican los pechos, y no la espalda. Otra consideración importante es que los pechos colgantes en dirección de la falda sugieren que la figura está en posición normal, es decir, erecta y no en posición descendente como se le ha reproducido en libros y artículos (con excepción del libro Imagen de Tláloc de Rubén Bonifaz publicado en 1986). Más adelante daré otras razones de el porqué la figura no es descendente pero desde aquí quiero dejar asentado que los monstruos de la tierra presentan la cabeza hacia arriba como puede verse en los códices.

Estudio comparativo de Tláloc Tlaltecuhtli. Es necesario hacer un estudio más detallado de la imagen de Tláloc Tlaltecuhtli la cual aparece frecuentemente en las bases de algunas esculturas mexicas. Uno de los ejemplos más importantes de Tláloc Tlaltecuhtli es el de la base de la famosa escultura de Coatlicue el cual está asociado a la fecha uno conejo, nombre calendárico de la Tierra ${ }^{7}$ (figura 5). A Tláloc Tlaltecuhtli se le representa generalmente con el rostro y el cuerpo vistos frontalmente y los miembros flexionados a los lados en una postura que se ha interpretado como la de parto. Al centro del cuerpo lleva un círculo rodeado con franjas, probablemente plumas, y adentro del círculo hay un cuadrado con un quinterno. A los lados del círculo y de su parte inferior emergen tres elementos

${ }^{3}$ Klein, 1980, pp 162-164 y figura 4.

${ }_{5}^{4}$ Historia de los Mexicanos por sus piniuras, p. 30.

${ }_{6}^{5}$ Histoire du Mexique, p. 103.

${ }_{7}^{6}$ Sullivan, 1974.

7 Uno de los conjuros anotados por Ruíz de Alarcón que se refiere a la Tierra dice lo siguiente: "Mi madre Señora de la Tierra Con la cabeza cariarriba Mi padre 1 conejo" Ruiz de Alarcón, 1982, p. 182. 
alargados y puntiagudos que semejan plumas. El tipo de tocado es igual al descrito en el relieve aquí tratado.

En el caso de nuestro relieve se trata de un aspecto femenino del Tláloc Tlaltecuhtli ya descrito como lo indican los pechos y la falda. Otras diferencias con el Tláloc Tlaltecuhtli son: el ollin que sustituye al quinterno, el tipo de ojos y la manera de figurar el labio superior. Como éste es el único ejemplo hasta ahora encontrado de la variante femenina no es posible saber si estas modificaciones se debieron al cambio de género.

Las corrientes acuáticas que rodean a nuestra figura y las calaveras y huesos de su faldellín la identifican con la parte femenina del cosmos, la región de la tierra, agua y muerte. ${ }^{9}$ Los símbolos acuáticos también pueden referirse a las aguas primordiales en la cual los dioses crearon a la Tierra.

El quintermo y el glifo ollin. Hay varias preguntas que nos podemos plantear acerca de Tláloc Tlaltecuhtli. La primera es sobre el significado que tenía. Me referiré primero a los ejemplares de esta deidad que llevan un quinterno en el centro del cuerpo. Para mí este quinterno se asocia con el concepto de los cuatro puntos cardinales y el centro. ${ }^{10}$ Esquemas semejantes a este quinterno se dibujaron en las páginas 25, 27 y 28 del Códice Borgia; en ellos hay rectángulos en los centros con cuatro divisiones a sus alrededores. En los tres casos Seler interpreta a los dioses del centro como alusivos a dicha dirección y a los otros dioses como indicativos de los puntos cardinales. ${ }^{11}$

El uso del quinterno se remonta por lo menos hasta Teotihuacan y en este sitio se le ha interpretado como un símbolo relacionado al jade, al color verde $o$ azul $y$, en general, al agua. ${ }^{12}$ Ya para la época de los mexicas quizá se le asociara también con el sol como comenta Herman Beyer en su artículo sobre la Piedra del Sol. ${ }^{13}$ No sería difícil que este símbolo tuviera varias asociaciones a través del tiempo. Cecilia Klein considera que Tláloc estaba relacionado al centro, lo cual sería otro argumento para

\footnotetext{
${ }^{8}$ Hay diversidad de opiniones acerca del género de los monstruos terrestres, es decir, si son masculinos, femeninos o bisexuales. En general las representaciones de Tláloc Tlaltecuhtli llevan lo que parecen ser tapararabos. Cono los torsos de los mismos muestran quinternos enmarcados no podemos saber si tenían pechos; es posible que se trata de imágenes masculinas.

${ }^{9}$ Para la identificación de la parte femenina del cosmos y del inframundo como la región de la tierra, agua y muerte ver López Austin, 1987, p. 271.

${ }^{10}$ Gutiérrez Solana, 1983 , p. 120 .

${ }^{11}$ Seler, 1963, en el facsínil del códice.

12 Winning, 1987, tomo I, p. 104

13 Beyer, 1965, p. 217.
} 
interpretar al quinterno como una alusión a esta dirección. ${ }^{14}$ Nicholson opina que tanto las figuras de Tláloc Tlaltecuhtli, como otras con chalchihuites en lugar de quinternos, representan al centro de la Tierra. ${ }^{15}$ Por su parte Constanza Vega, en su estudio sobre la cerámica mexica, considera asimismo que el quinterno corresponde a las cinco direcciones del mundo. ${ }^{16}$

Nuestro relieve es el único caso, hasta ahora conocido, en el cual el quinterno fue reemplazado por el glifo ollin aquí dibujado con un ojo a medio cerrar como aparece en la lámina 14 del Códice Borbónico. Es posible pensar que el Tláloc Tlaltecuhtli masculino (que porta el maxtlatl) es el que presenta el quinterno pero, cuando se le transforma al género femenino con pechos y falda, se sustituye al quinterno por el glifo ollin. Habrá que esperar a ver si se encuentra alguna otra pieza para comprobar esta hipótesis. ${ }^{17}$

Para Seler el glifo ollin estaba relacionado con el sol, ${ }^{18} \sin$ embargo, según Cecilia Klein, este signo estaba asociado al mismo tiempo con Tláloc. ${ }^{19}$ Otra posible explicación acerca del glifo ollin en este relieve es que dicho glifo se refiere asimismo a los temblores; podría ser entonces la representación de Tlalli iyollo (corazón o centro de la tierra) la deidad de los temblores.

La posición ascendente de la figura. Otra interrogante acerca de Tláloc Tlaltecuhtli y su aspecto femenino es en cuanto a su posición. Como ya dije anteriormente, la posición de la figura es ascendente. En un estudio anterior demostré que en los códices los monstruos terrestres siempre son ascendentes y que, en muchos casos, emergen diversos elementos de sus bocas. ${ }^{20}$ También ya mencioné la escultura del monstruo terrestre, hallada en el metro de la Ciudad de México, la cual presenta la cara hacia arriba.

Otra pieza que hay que tomar en cuenta para reforzar la posición ascendente del relieve aquí estudiado es la vasija de piedra conservada en el

\footnotetext{
${ }^{14}$ Klein, Op. cit., p. 157. Klein identifica al quinterno como la cruz kan que simbolizaba originalmente al sur entre los mayas. Pero, más adelante, agrega: "el centro del universo estaba asociado con la Tierra y se intercambiaba frecuentemente con el sur". Klein, 1975, pp. 74 y 81 .

${ }^{5}$ Nicholson, 1967, p. 83. Es interesante que las imágenes de Tláloc Tlaltecuhtli carecen de puños de piel que según este mismo autor identifica a las deidades asociadas al oeste. Nicholson, 1954, p. 166.

${ }_{17}^{16}$ Vega, 1979.

${ }^{17}$ El relieve aquí analizado no parece haber sido esculpido en la base de una escultura y esto sería otra diferencia con el Tláloc Tlaltecuhtli masculino.

${ }_{18}^{18}$ Seler, Op cit, tomo I, p. 150

${ }^{19}$ Klein, Op cit, p 165 .

20 Gutiérrez Solana, Op cit, p. 19
} 
Museum für Völkerkunde de Viena la cual fue analizada cuidadosamente por Seler..$^{21}$ En esta vasija hay dos monstruos relacionados con la Tierra, uno en la base y el otro en la parte posterior. El primero es del tipo zoomorfo carente de mandíbula inferior y de él emerge la cara, en alto relieve, que adorna la parte frontal de la pieza (figura 6). Este monstruo tiene varias semejanzas con el que trato en este artículo como son: la falda con calaveras y huesos decorada con una orilla con divisiones que figuran flecos; el glifo ollin con el ojo a medio cerrar dispuesto sobre el cuerpo, y el hecho de que emerja una cara de su boca. Además abajo del monstruo se dispusieron símbolos acuáticos. En el caso del relieve aquí estudiado es curioso que las calaveras de la falda estén viendo hacia arriba y no hacia abajo, como debería de ser. Creo que la razón se debe a que el faldellín, en esta representación, da vuelta entre las piernas para subir sobre la parte frontal de la figura.

El monstruo de la parte posterior de la vasija tiene tres rasgos similares a nuestro relieve (figura 7). El primero es su posición ascendente, el segundo es la colocación de la cabeza echada hacia atrás sobre lo que resulta ser el frente en lugar de la espalda de la figura y, en tercer lugar, los pechos al descubierto.

Una consideración importante acerca de la variante de Tláloc Tlaltecuhtli de nuestro relieve es el porqué aparece con la cabeza echada hacia atrás cuando en las representaciones masculinas la cabeza está en posición normal. Me parece que es porque se quería representar una cara saliendo de su boca lo cual no sería posible de otra manera. ${ }^{22}$

El glifo junto a la falda de Tláloc Tlaltecuhtli. Dicho glifo está incompleto por la rotura del monolito pero aun así puede apreciarse que se trata de una superficie resaltada y curva en la cual aparecen incisos varios elementos en forma de "U"s invertidos. Este glifo es muy semejante al empleado para representar a Tlatelolco ${ }^{23}$ (figura 8). Robert $\mathrm{H}_{\text {. Barlow nos dice que }}$ Tlatelolco, que se nombraba también Xaltilolli o Xaltiloloco, significa el lugar o montón redondo de arena. ${ }^{24}$

El glifo puede estar relacionado con la imagen de Tláloc Tlaltecuhtli y podria reforzar el concepto de tierra que, como ya explicamos, es esencial

\footnotetext{
21 Seler, 1904.

${ }^{22}$ Seler explica la posición extraña de la figura de la parte posterior de la vasija ya mencionada diciendo que la cabeza vuelta hacia atrás simboliza el "apartarse de la luz $\ldots$ y el hundirse de cabeza en la Tierra" (Seler, 1963, tomo I, p. 143).

${ }^{23}$ Así se dibujo el nombre de Tlatelolco en el Códice Vaticano A (lámina CXVI), en el Códice Mendocino $y$ así se esculpió en la Piedra de Tizoc.

${ }^{24}$ Barlow, 1987, p. 65
} 
en dicha imagen e inclusive podría indicar una conexión de la misma con la arena.$^{25} \mathrm{Al}$ respecto hay que recordar que en varias ofrendas del Templo Mayor (por ejemplo en la cámara II y en la ofrenda 1 entre otras) se encontró arena. La arena parece que indicaba una asociación con el mar el cual para los mexicas "era el símbolo de la fertilidad absoluta incorporada en el agua". ${ }^{26}$ Gordon Brotherston, en su artículo "Sacred Sand in Mexican Picture-writing and Later Literature", observa que en uno de los himnos sagrados nahuas se describe al Tlalocan como un lugar acuático donde hay arena esparcida; quizá en nuestro relieve los símbolos acuáticos, aunados al glifo ya mencionado, se refieran al Tlalocan.

La otra posibilidad es que el glifo se refiera a la ciudad de Tlatelolco. No son muy numerosas las esculturas mexicas con glifos de lugares. Emily Umberger menciona a las siguientes: la Piedra de Tizoc, la estela de Huitzuco, el Teocalli de la Guerra Sagrada, los relieves del Peńón de los Baños y Tetzcotzingo (ver Umberger, s.f., p. 136); a éstas hay que agregar la nueva pieza hallada en el Ex arzobispado. En algunos de estos monumentos se conmemoran las conquistas hechas por los mexicas pero hay que advertir que en varios de éstos se incluyen las fechas en que dichas conquistas fueron realizadas. No podemos saber, en el caso de nuestro monolito, si tendría o no fecha por la rotura de la piedra. Es de interés que Cecilia Klein sugiere que el chalchihuitl que aparece en un Tlaltecuhtli, labrado en una piedra verde, puede referirse a la conquista de Chalco por los mexicas llevada a cabo en $1465 .{ }^{27}$ Hay entonces la posibilidad de que nuestro relieve pudiera estar asociado a la conquista de Tlatelolco, que tuvo lugar en 1473, o a algún otro episodio en la historia de esta ciudad.

\section{Tlaloc Tlaltecuhtli y sus antecedentes teotihuacanos}

Es interesante indagar acerca del origen de Tláloc Tlaltecuhtli ya que su imagen no aparece en los códices ya sea los pintados en la época prehispánica o en la colonial. Tampoco se encuentra en las esculturas toltecas que, en varios casos, forman un antecedente directo para las piezas mexicas. Es en el arte teotihuacano donde hallamos los elementos que los mexicas utilizaron para representar a Tláloc Tlaltecuhtli.

\footnotetext{
${ }^{25}$ Agradezco al doctor Xavier Noguez esta observación.

26 Broda, 1987, p. 223.

27 Ver Pasztory, 1983, p. 152 en la cual cita a Klein
} 
Esther Pasztory, en su estudio sobre la iconografía teotihuacana, logró distinguir entre dos tipos de Tlálocs: el llamado Tláloc A relacionado principalmente con el agua y el Tláloc $B$ asociado sobre todo con el jaguar y el cual era numen de la guerra y del sacrificio del corazón ${ }^{28}$ Según Hasso von Winning, Tláloc B tenía asimismo ciertas conexiones secundarias con la tierra y el agua ${ }^{29}$ Del Tláloc B se derivó, como veremos, el Tláloc Tlaltecuhtli aunque sus funciones y asociaciones en las dos culturas no eran exactamente las mismas ya que entre los mexicas era fundamentalmente el Señor de la Tierra y del Inframundo.

El glifo de Tláloc B en Teotihuacan ha sido analizado por Hasso von Winning. ${ }^{30}$ Consiste de tres círculos arriba del labio superior de Tláloc, labio que encierra un quinterno. Según nos explica este autor, el labio estilizado da vuelta en sus extremos hacia arriba lo cual es característico del Tláloc B. Es importante también que en algunos casos dicho dios usa un tocado con tres elementos como se puede ver en una figurilla de Zacuala. En esta figurilla Tláloc B lleva una banda en el tocado con tres discos justo como lo encontramos en el Tláloc Tlaltecuhtli (figura 9). Hasso von Winning explica que el glifo de Tláloc B "no aparece en la pintura sino únicamente en las almenas de barro y en la cerámica y es tardío debido a que la cerámica que lo muestra corresponde a la fase Xolalpan y Metepec" ${ }^{31}$ En los dibujos de la (figura 10) se ve claramente cómo los rasgos del Tláloc Tlaltecuhtli mexica se derivan del glifo de Tláloc B. El maxtlatl que ostenta Tláloc Tlaltecuhtli se deriva posiblemente del símbolo del año empleado por los teotihuacanos pero en posición invertida. $^{32}$

Hay otros dos rasgos de Tláloc Tlaltecuhtli que provienen asimismo de Teotihuacan. Uno de ellos es el uso de un círculo con plumas para enmarcar a un quinterno; así aparece en los marcos de uno de los tableros del pequeño adoratorio en el llamado patio pintado de Atetelco. También se pintó en un mural del Palacio del Sol en la zona $5 \mathrm{~A}$; en este caso el medallón con el quinterno formado por entrelaces sustituye al rostro de una figura. El segundo rasgo es parte del tocado de Tláloc Tlaltecuhtli y consiste de dos franjas formadas por triángulos las cuales emergen de la banda frontal del mismo; dichos extremos dan

\footnotetext{
${ }_{28}^{28}$ Pasztory, 1971

${ }^{29}$ Winning, Op cit, p 66

${ }^{30}$ Ibid, pp 65 y 66.

${ }^{31} \mathrm{Ibid}, \mathrm{p} 66$.

${ }^{32}$ Klein, $O p$. cit., p. 182
} 
vuelta hacia arriba. En el mural de la llamada Diosa de Jade de Teotihuacan encontramos estas mismas franjas como parte de su tocado. ${ }^{33}$

El uso de elementos de la tradición teotihuacana se debió a que los mexicanos los consideraban particularmente sacros. En las ofrendas del Templo Mayor aparecieron objetos teotihuacanos y teotihuacanoides además de que se hicieron en dicho sitio edificios inspirados en las construcciones de Teotihuacan; todo ello demuestra que los mexicas tenían un interés especial en vincularse con el pasado mítico. ${ }^{34}$

\section{La importancia simbólica de Tláloc Tlaltecuhtli}

El último aspecto que trataremos en relación a Tláloc Tlaltecuhtli es el porqué se convirtió en una imagen importante que se labró en las bases de un número considerable de piezas, algunas tan notables como la Coatlicue y la Yolotlicue. Aquí me refiero al Tláloc Tlaltecuhtli con el quinterno sobre el torso, quinterno simbólico del centro. La razón es que Tenochtitlan, y especialmente su centro ceremonial, eran considerados como la capital no sólo del imperio mexica sino además como el centro del mundo. El Templo Mayor era "el templo principal del imperio, el centro tanto material como simbólico del estado más poderoso de Mesoamérica en el momento de la Conquista". ${ }^{35}$ Eduardo Matos expresa una idea similar al explicar que en el Templo Mayor se enterraban joyas venidas de las diversas partes del imperio porque así "el centro del mundo expresaba su dominio sobre la periferia" ${ }^{36}$

\section{La iconografia del relieve en su conjunto}

La pieza, tema de nuestro estudio, se puede interpretar en su conjunto de

${ }^{33}$ Es curioso que en nuestra pieza los miembros de la figura tengan un contorno doble. En los relieves de Tláloc Tlaltecuhtli con maxtaltl los miembros superiores también lo presentan. En alguno de estos últimos los contornos internos de los brazos se originan en volutas (como puede verse en la base de la Coatlicue) lo cual recuerda a algunas pinturas de Teotihuacan en las cuales los miembros ostentan también volutas (ver Winning, 1987, tomo I, cap. VIII, fig. 9b; tomo II, cap VI, fig. 4f).

${ }^{34}$ Al respecto ver el libro La Recuperación Mexica del Pasado Teotihuacano de Leonardo López Luján y el artículo de Alfredo López Austin sobre "The Masked God of Fire"

${ }_{35}$ Broda, Carrasco y Matos, 1987, p 7.

36 Ibid., p. 38 
dos maneras dependiendo sobre todo de la posición original en que estaba colocada. La primera alternativa es que, de estar erigida verticalmente, la figura de Tláloc Tlaltecuhtli sería ascendente y de su boca saldría el rostro del Dios de la Lluvia Encontramos un paralelo a esta representación en el dibujo del Tonalámatl de Aubin correspondiente a la decimosexta trecena (figura 11). En él aparece, al lado izquierdo del recuadro principal, un monstruo terrestre del cual emerge la cara de Tláloc con su ojo, boca y dientes característicos; este conjunto ha sido identificado como Tlalchitonatiuh, el sol que asciende de la Tierra o desciende a la Tierra. Se trata del mismo conjunto que en nuestro relieve: un monstruo terrestre del cual emerge Tláloc. En dicho tonalamatl este monstruo presenta rasgos zoomorfos pero el concepto es el mismo. El Tláloc de dicho manuscrito tiene, detrás de la nuca, un disco solar mientras que en nuestro relieve tenemos al glifo ollin, que también se refiere al sol, aunque labrado sobre el cuerpo de Tláloc Tlaltecuhtli. Tanto en el relieve, como en el Tonalámatl de Aubin, las imágenes están asociadas con corrientes acuáticas.

Seler, en su estudio sobre Tlachitonatiuh y el glifo ollin, nos dice que el ollin no se refiere al movimientó del sol "por el cielo claro o el cielo oscuro, sino su movimiento hacia la Tierra, su hundirse en la Tierra (o, en sentido inverso su surgimiento de la Tierra) ${ }^{\prime \prime}{ }^{37}$ Dicho autor llegó a esta interpretación porque el nombre maya para ollin no es movimiento sino caban que significa la tierra o terremoto.

Tlalchitonatiuh está representado también en los códices Borbónico, Telleriano Remensis y Vaticano $A$ (figura 12). En este último, el comentarista llama a la figura Tlachitonatic y dice lo siguiente acerca de ella:

Esto significa entre la luz y las tinieblas, to que nosotros llamamos crepúsculo, y así pintan esta figura de la redondez de la tierra como un hombre que tiene sobre la espalda al sol, y bajo los pies la noche y la muerte, dando a entender que cuando el sol va a morir, va a calentar e iluminar a los muertos. ${ }^{38}$

Lo que el cronista identifica como la noche y la muerte se puede interpretar como el monstruo de la tierra.

La otra alternativa posible se basa en la hipotética colocación horizontal del monolito (al igual que el relieve de la Coyolxauhqui). En este caso es probable que represente a Tláloc Tlaltecuhtli como cem-anahuac, es decir, a la Tierra flotando sobre las aguas primordiales. Los mitos nos relatan cómo los dioses creadores "hicieron el agua y en ella criaron a un peje grande y de

\footnotetext{
${ }^{37}$ Seler, Op cit, tomo I, p. 16

${ }^{38}$ Códice Valicano $A$, lámina XLVI.
} 
este peje hicieron la Tierra". ${ }^{39}$ El rostro de Tláloc y las corrientes acuáticas ${ }^{40}$ se referirían no sólo al océano primordial sino al agua existente bajo la Tierra ya que como nos explica Sahagún: "La mar anda por debajo de la tierra y de los montes; y por donde halla camino para salir fuera, allí mana, o por las raíces de los montes, o por lós llanos de la tierra. ${ }^{\mathbf{4 1}}$

Para concluir diremos que los hallazgos del Templo Mayor han permitido ampliar nuestros conocimientos sobre la sociedad mexica en muchos aspectos pero, a la vez, han planteado nuevas interrogaciones. A través del estudio de las piezas descubiertas podemos darnos cuenta de cómo los mexicas estaban en un proceso continuo de crear nuevos complejos iconográficos. En algunos casos para crear estos complejos utilizaban elementos de culturas antiguas como la teotihuacana y la tolteca, a los cuales les daban significados novedosos. Estos nuevos complejos deben de haber correspondido a modificaciones en la estructura social o política y también en la ideología del mundo mexica. ${ }^{42}$

\section{BIBLIOGRAFÍA}

\section{Barlow, Robert $\mathrm{H}$.}

1987 Tlatelolco, rival de Tenochtitlan (J. Monjarás-Ruiz, Elena Limón y María de la Cruz Paillés, editores), vol. 1, INAH, UDLA, México.

Beyer, Herman

1965 "El llamado Calendario Azteca", El México Antiguo, tomo X, pp. 123- 256, México.

\section{Bonifaz, Rubén}

1986 Imagen de Tláloc, UNAM, México.

Broda, Johanna

1987 "The Provenience of the Offerings: Tribute and Cosmovision", The Aztec Templo Mayor, Dumbarton Oaks, Washington, D.C., pp. 211 256.

${ }_{40}^{39}$ Hítôrià de los Mexicanos por sus pinturas, p. 25

40 Es posible que los chorros de agua emergentes a los lados del rostro de Tláloc sean los brazos del mismo pues parece haber restos de un pulgar al final del chorro que se conserva completo.

${ }_{41}^{4}$ Sahagún, 1956, tomo III, p. 345.

42 Cecilia Klein y Hasso von Winning me permitieron usar sus dibujos por lo cual les estoy agradecida. Hasso von Winning leyó este artículo y le agradezco mucho sus valiosos comentarios. Expreso mi gratitud a Gracy Solana de Arizpe por las fotografias que tomó para acompañar a este artículo. 
David Carrasco y Eduardo Matos

1987 The Great Temple of Tenochtitlan, University of California Press, Berkeley.

Brotherston, Gordon

1974 "Sacred Sand in Mexican Picture-writing and Later Literature", Estudios de Cultura Náhuatl, vol. XI, UNAM, México, pp. 303-310.

Códice Borbónico

1974 F.C.E., México.

Códice Borgia, ver Seler, E.

Códice Telleriano Remensis

1964 En: Antigüedades de México basadas en la recopilación de Lord Kingsborough, vol. 1, Secretaría de Hacienda y Crédito Público, México.

\section{Códice Vaticano A}

1964 En: Antigüedades de México basadas en la recopilación de Lord Kingsborough, vol. 3, Secretaría de Hacienda y Crédito Público, México.

Coe, Michael D. y Gordon Whittaker

1982 Aztec Sorcerers in Seventeenth Century México. The Treatise on Superstitions by Hemando Ruiz de Alartón, State University of New York at Albany.

Gutiérrez, Solana, Nelly

1983 Objetos ceremoniales en piedra de la cultura mexica, UNAM, México.

Historia de los mexicanos por sus pinturas

1965 En: Teogonía e Historia de los Mexicanos, Ed. Porrúa, México, pp. 23-90.

Histoire du Mexique

1965 En: Teogonía e Historia de los Mexicanos, Ed. Porrúa, México, pp. 91- 120.

Klein, Cecilia

1980 "Who Was Tlaloc?", Joumal of Latin American Lore, 6, 2, pp. 155204.

López Austin, Alfredo

1987 "The Masked God of Fire", The Aztec Templo Mayor, Dumbarton Oaks, Washington, D. C., pp. 257-291. 


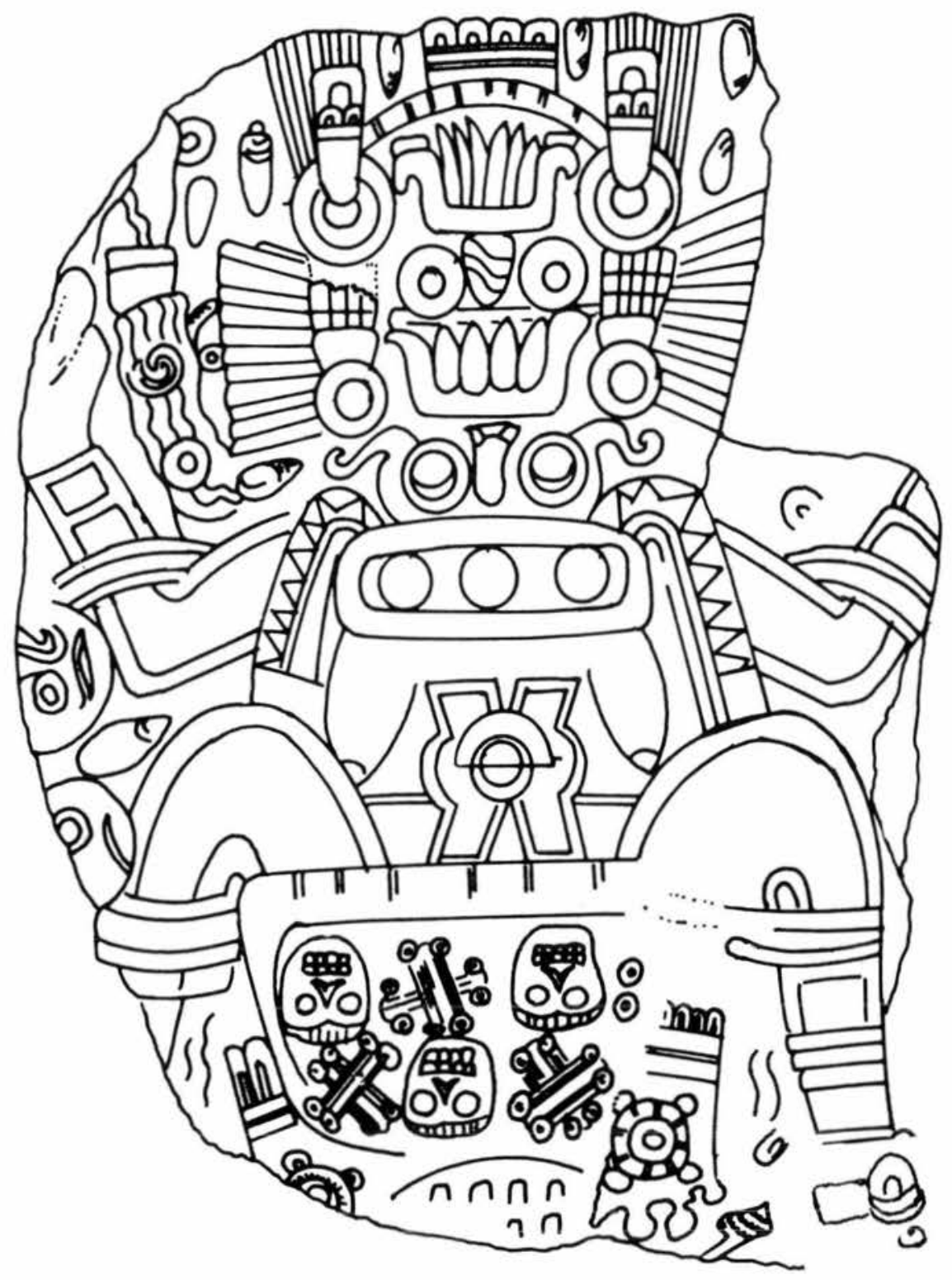

1. Dibujo de los dos fragmentos del relieve del Templo Mayor (basado en Klein, 1980, fig. 4 y en las fotografias de G. Solana de Arizpe). 

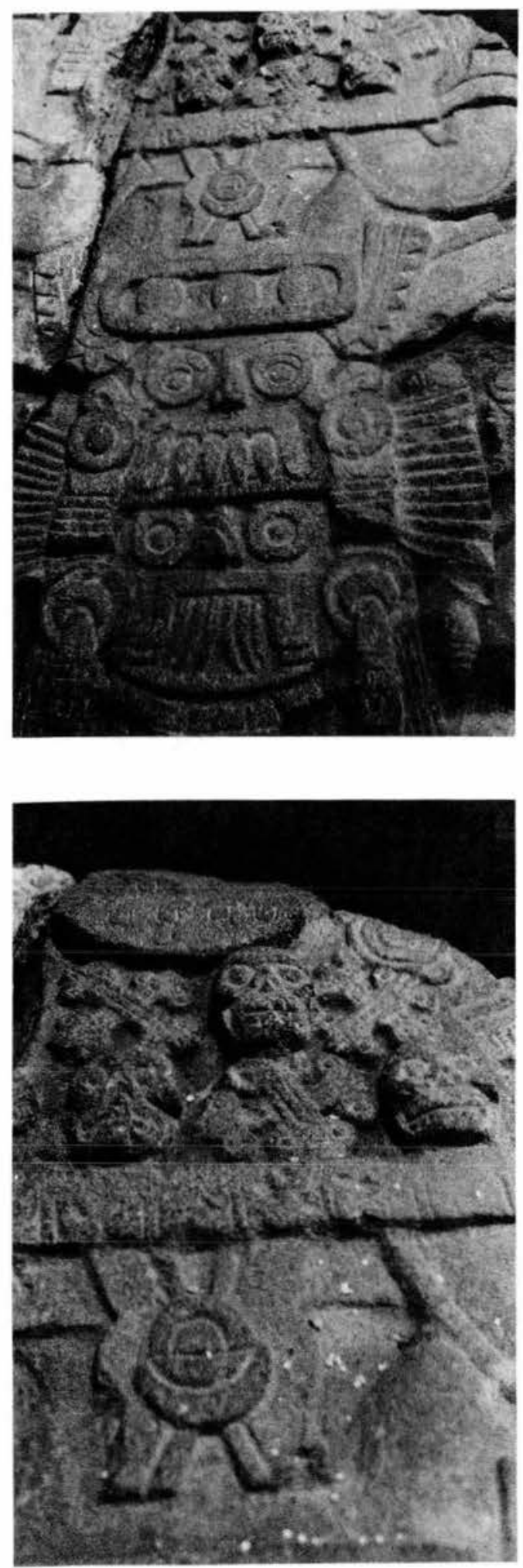

2. Relieve del Templo Mayor. Parte central (foto de Gracy Solana de Arizpe).

3. Relieve del Templo Mayor. Detalle con el glifo de la falda (foto de Gracy Solana de Arizpe). 
4. Relieve de la deidad de la vegetación, Cerro de la Malinche.
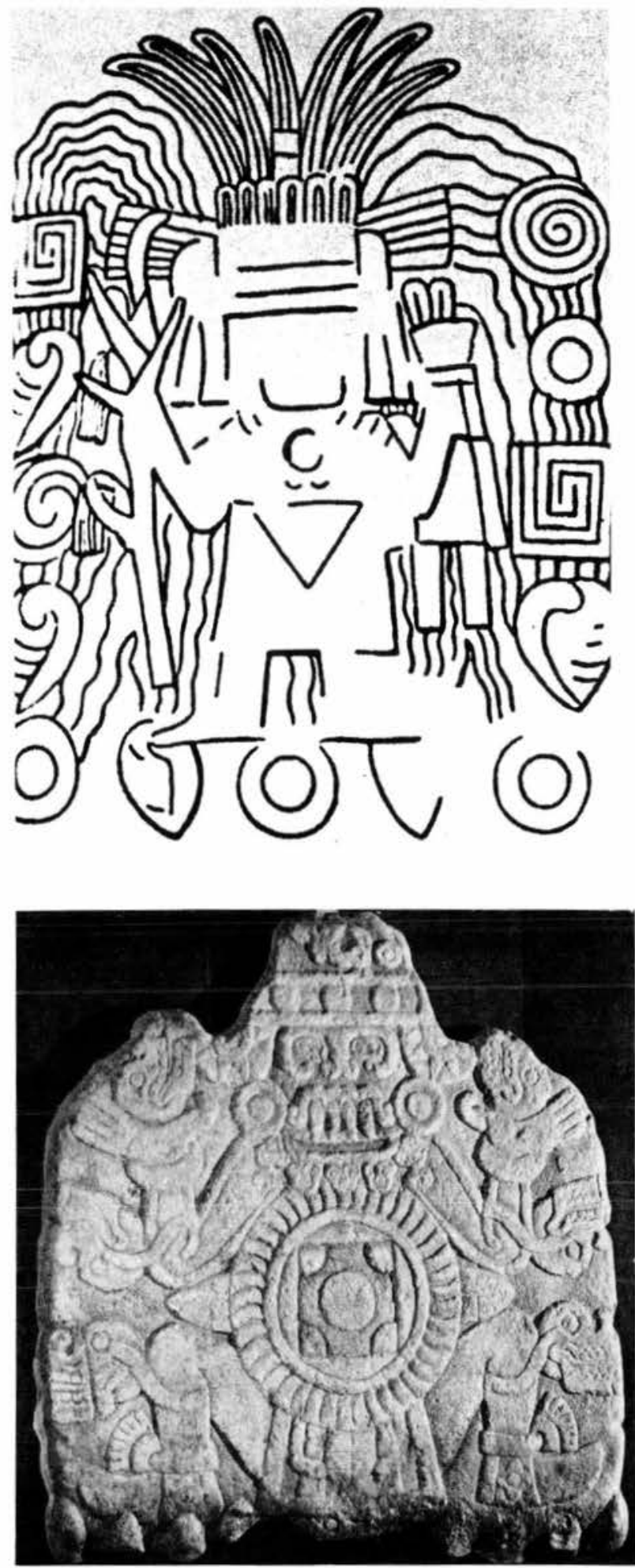

5. Tláloc Tlaltecuhtli, base de la Coatlicue. 
7. Monstruo de la Tierra.

Parte posterior de la vasija del Museum für Völkerkunde, Viena.
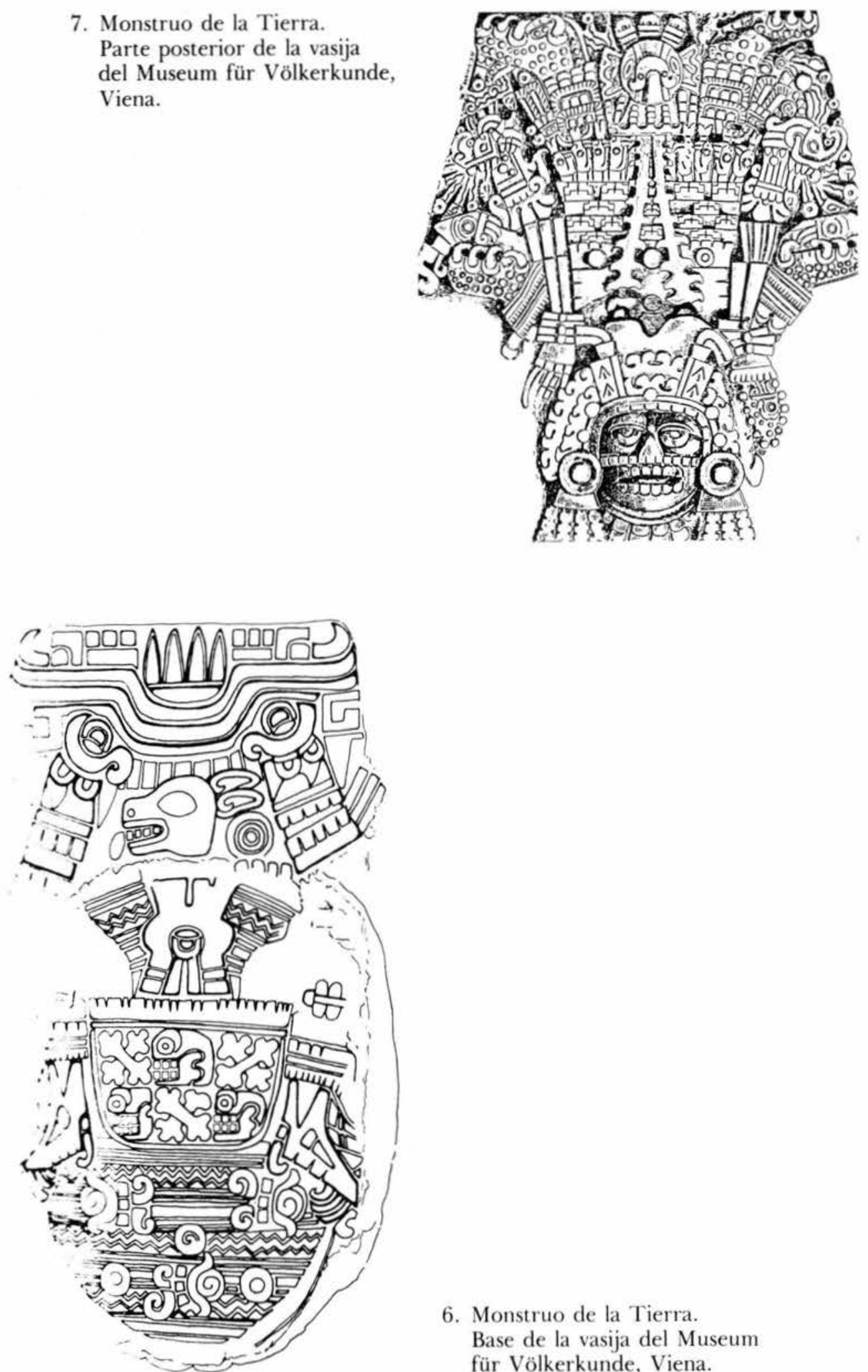

6. Monstruo de la Tierra.

Base de la vasija del Museum für Völkerkunde, Viena. 


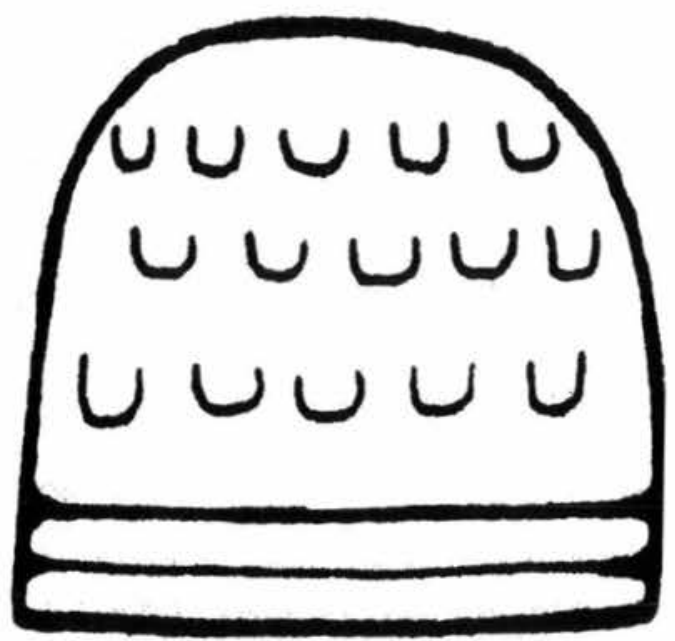

8. Glifos de Tlatelolco.

a) Piedra de Tizoc.

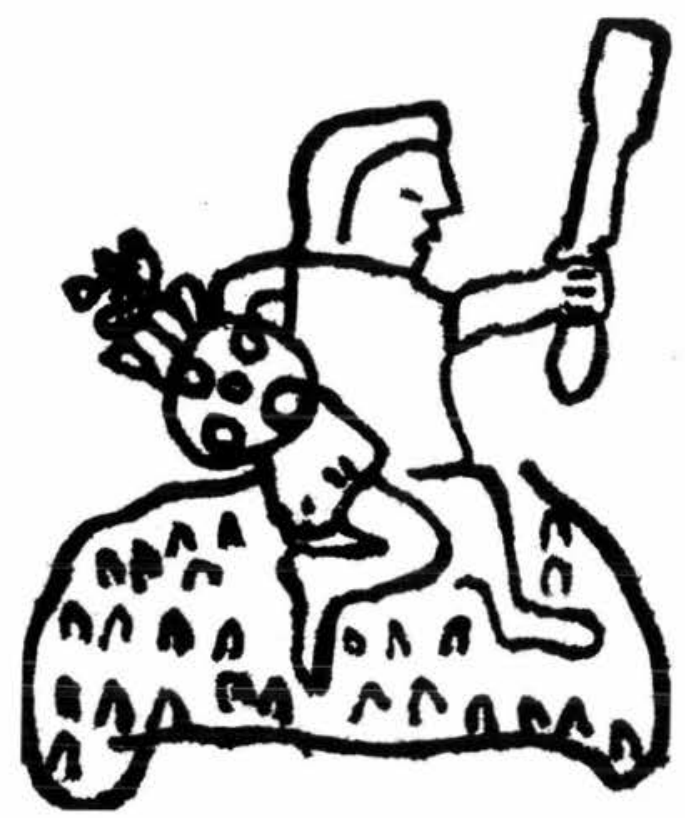

b) Códice Telleriano Remensis, lámina XIV.

Copia realizada por la autora. 


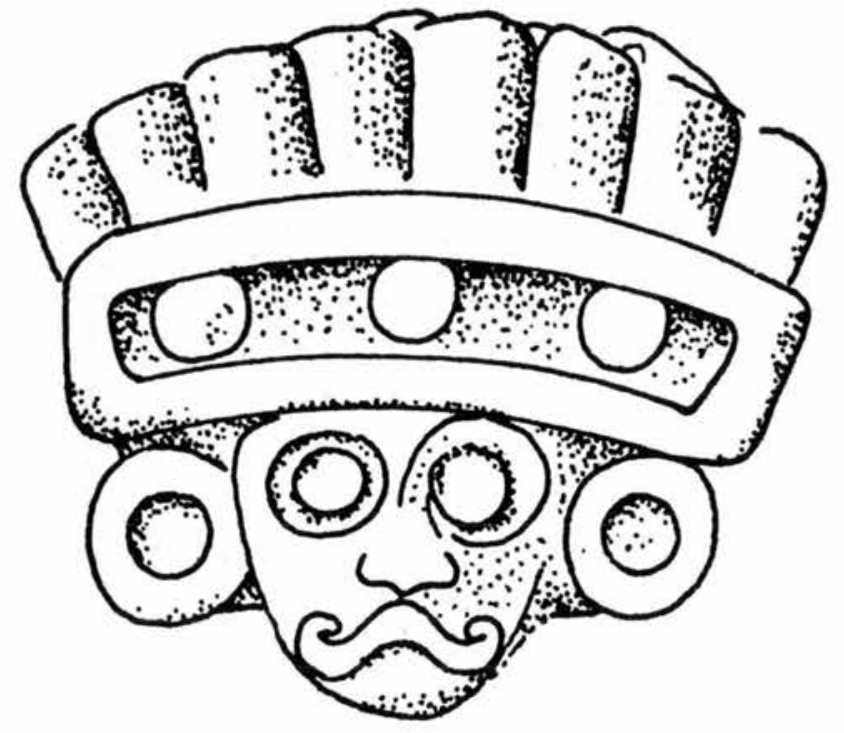

9. Figurilla de Zacuala.

Dibujo tomado de Winning, 1987, tomo I.

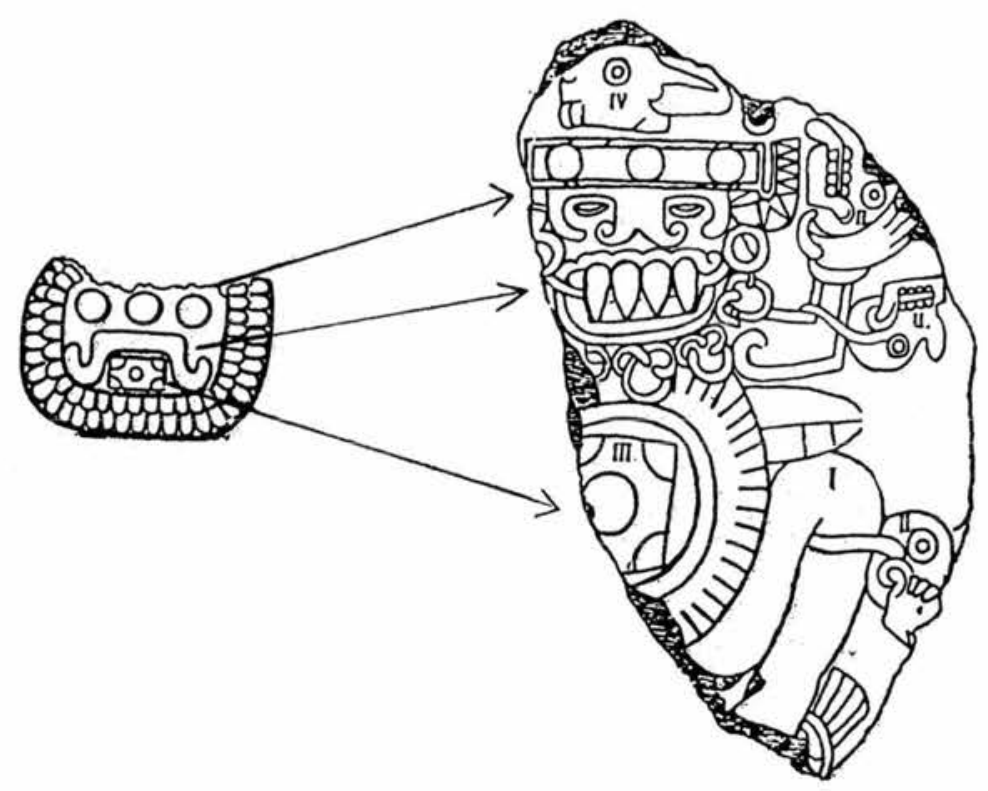

10. Evolución del glifo de Tláloc B al Tláloc Tlaltecuhtli. 


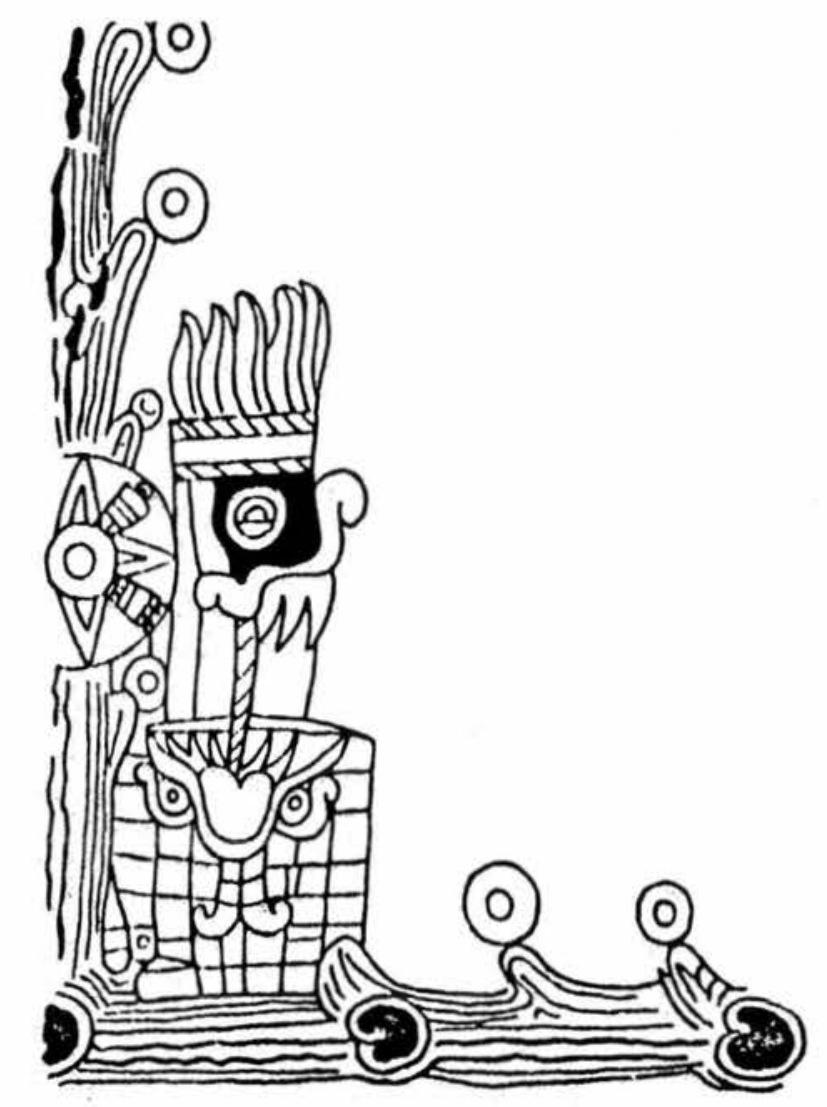

11. Tlalchitonatiuh, lámina 16 del Tonalámatl de Aubin. 

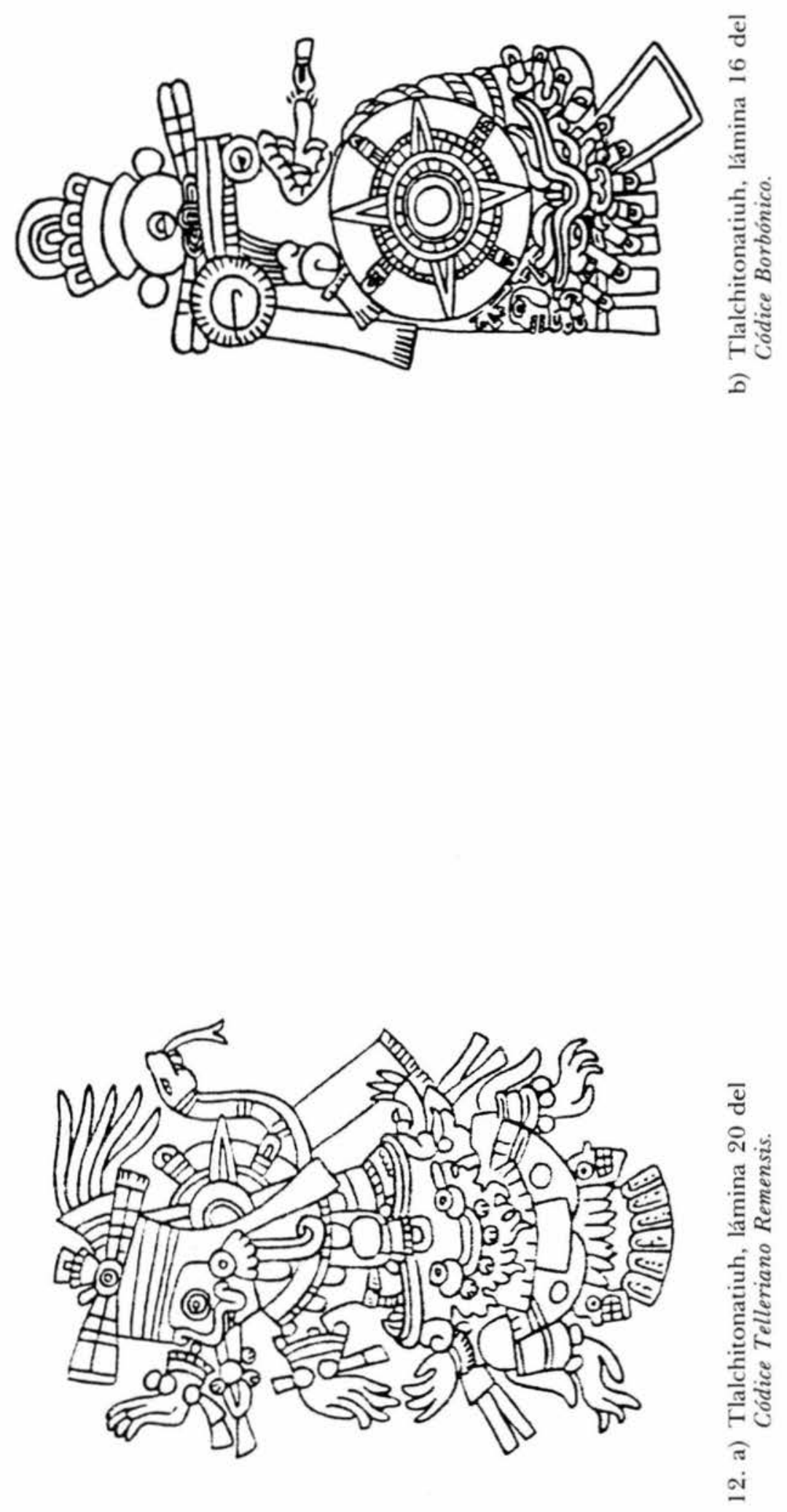


\section{López Luján, Leonardo}

1982 El Templo Mayor: Excavaciones y Estudios, INAH, México.

1984 "The Templo Mayor of Tenochtitlan: Economics and Ideology", Ritual Human Sacrifice in Mesoamerica, Dumbarton Oaks, Washington, D. C., pp. 133-164.

1989 La recuperación mexica del pasado teotihuacano, México.

Nicholson, Henry B.

1954 "The Birth of the Smoking Mirror", Archaeology, vol. 7, num. 3, Archaeological Institute of America, pp. 164-170.

1967 "A fragment of an Aztec relief carving of the Earth Monster", Joumal de la Société des Américanistes, tomo LVI, num. 1, París, pp. 80-94.

Pasztory, Esther

1974 The Iconography of the Teatihuacan Tlaloc, Dumbarton Oaks, Washington, D. C.

1983 Aztec Art, Harry N. Abrams, Inc., Nueva York. Ruiz de Alarcón, Hernando, ver Coe, M. D. y G. Whittaker.

Sahagún, Bernardino de

1956 Historia General de las Cosas de la Nueva España, Ed. Porrúa, México.

Seler, Eduard

1904 "La vasija de pulque de la colección Bilimek en el Museo K. K. de

Historia Natural", Gesammelte Abhandlungen zur Amerikanischen

Sprach-und Altertumskunde, vol 2, pp. 913-952.

1963 Comentarios al Códice Borgia, F. C. E., México, Tonalámatl de Aubin. 1981 El Tonalámatl de Aubin, Tlaxcala, México.

Umberger, Emily

s. f. Aztec Sculptures, Hieroglyphs, and History, tesis doctoral, Columbia University.

Vega, Constanza

1979 Simposio sobre Problemas de la Iconografía del Arte Mesoamericano Posclásico, XLIII Congreso Internacional de Americanistas.

Winning, Hasso von

1987 La Iconografía de Teotihuacan, tomos 1 y 2, UNAM, México. 